\title{
Deleting myeloid IL-10 receptor signalling attenuates atherosclerosis in LDLR-/- mice by altering intestinal cholesterol fluxes
}

DOI:

10.1160/TH16-01-0043

\section{Document Version}

Accepted author manuscript

Link to publication record in Manchester Research Explorer

Citation for published version (APA):

Stöger, J. L., Boshuizen, M. C. S., Brufau, G., Gijbels, M. J. J., Wolfs, I. M. J., van der Velden, S., Pöttgens, C. C. H., Vergouwe, M. N., Wijnands, E., Beckers, L., Goossens, P., Kerksiek, A., Havinga, R., Müller, W., Lütjohann, D.,

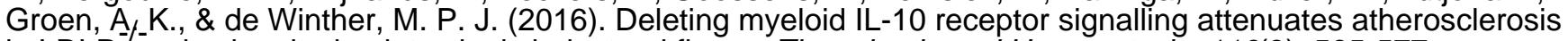
in LDLR ${ }^{-1}$ mice by altering intestinal cholesterol fluxes. Thrombosis and Haemostasis, 116(3), 565-577. https://doi.org/10.1160/TH16-01-0043

Published in:

Thrombosis and Haemostasis

\section{Citing this paper}

Please note that where the full-text provided on Manchester Research Explorer is the Author Accepted Manuscript or Proof version this may differ from the final Published version. If citing, it is advised that you check and use the publisher's definitive version.

\section{General rights}

Copyright and moral rights for the publications made accessible in the Research Explorer are retained by the authors and/or other copyright owners and it is a condition of accessing publications that users recognise and abide by the legal requirements associated with these rights.

\section{Takedown policy}

If you believe that this document breaches copyright please refer to the University of Manchester's Takedown Procedures [http://man.ac.uk/04Y6Bo] or contact uml.scholarlycommunications@manchester.ac.uk providing relevant details, so we can investigate your claim.

\section{OPEN ACCESS}


1 Deleting myeloid IL-10 receptor signalling attenuates atherosclerosis in $\mathrm{LDLR}^{-/-}$mice by

2 altering intestinal cholesterol fluxes

3

4 Running title: Myeloid IL-10R signalling is pro-atherogenic

5

6 J. L. Stöger ${ }^{1,2}$, M.C.S. Boshuizen ${ }^{1 *}$, G. Brufau ${ }^{3}$, M.J.J. Gijbels ${ }^{1,2,4}$, I.M.J. Wolfs ${ }^{4}$, S. van der Velden ${ }^{1}$,

7 C.C.H. Pöttgens ${ }^{2}$, M.N. Vergouwe ${ }^{2}$, E. Wijnands ${ }^{4}$, L. Beckers ${ }^{1}$, P. Goossens ${ }^{2,5}$, A. Kerksiek ${ }^{6}$, R. Havinga ${ }^{3}$,

8 W. Müller ${ }^{7}$, D. Lütjohann ${ }^{6}$, A.K. Groen ${ }^{3,8}$, M.P.J. de Winther ${ }^{1}$

9

* Authors contributed equally

1. Experimental Vascular Biology, Department of Medical Biochemistry, Academic Medical Center, University of Amsterdam, Amsterdam, The Netherlands

2. Molecular Genetics, Cardiovascular Research Institute Maastricht, Maastricht University Medical Center, Maastricht, The Netherlands

3. Pediatrics and Laboratory Medicine, University of Groningen, University Medical Center Groningen, Groningen, The Netherlands

4. Pathology, Cardiovascular Research Institute Maastricht, Maastricht University Medical Center, Maastricht, the Netherlands

5. Centre d'Immunologie de Marseille-Luminy, Aix-Marseille Université, Marseille, France

6. Institute for Clinical Chemistry and Clinical Pharmacology, Medical University Clinics Bonn, Bonn, Germany

\section{Faculty of Life Sciences, University of Manchester, Manchester, United Kingdom}

8. Amsterdam Diabetes Center, Academic Medical Center, University of Amsterdam, Amsterdam, The Netherlands

\section{Corresponding Author:}

Prof. M.P.J. de Winther, PhD

Experimental Vascular Biology, Medical Biochemistry

Academic Medical Center, University of Amsterdam

Meibergdreef 15, 1105 AZ Amsterdam, The Netherlands

E-mail: m.dewinther@amc.uva.nl

Telephone: +31205666762

Word count: 4978

Financial support: Menno P.J. de Winther is an established investigator of the Netherlands Heart Foundation (2007T067). He is supported by the Netherlands Heart Foundation (\#2010B022 and CVON 2011/ B019: 

fellowship.

\section{Abstract}

Inflammatory responses and cholesterol homeostasis are interconnected in atherogenesis. IL-10 is an important anti-inflammatory cytokine, known to suppress atherosclerosis development. However, the specific cell types responsible for the atheroprotective effects of IL-10 remain to be defined and knowledge on the actions of IL-10 in cholesterol homeostasis is scarce. Here we investigated the functional involvement of myeloid IL-10-mediated atheroprotection.

To do so, bone marrow from IL-10 receptor 1 (IL-10R1) wildtype and myeloid IL-10R1 deficient mice was transplanted to lethally irradiated female $\mathrm{LDLR}^{-/-}$mice. Hereafter, mice were given a high cholesterol diet for 10 weeks after which atherosclerosis development and cholesterol metabolism were investigated. In vitro, myeloid IL-10R1 deficiency resulted in a pro-inflammatory macrophage phenotype. However, in vivo significantly reduced lesion size and severity was observed. This phenotype was associated with lower myeloid cell accumulation and more apoptosis in the lesions. Additionally, a profound reduction in plasma and liver cholesterol was observed upon myeloid IL-10R1 deficiency, which was reflected in plaque lipid content. This decreased hypercholesterolemia was associated with lowered VLDL and LDL levels, likely as a response to decreased intestinal cholesterol absorption. In addition, IL-10R1 deficient mice demonstrated substantially higher faecal sterol loss caused by increased non-biliary cholesterol efflux. The induction of this process was linked to impaired ACAT2-mediated esterification of liver and plasma cholesterol. Overall, myeloid cells do not contribute to IL-10-mediated atheroprotection. In addition, this study demonstrates a novel connection between IL-10-mediated inflammation and cholesterol homeostasis in atherosclerosis. These findings make us reconsider IL-10 as a beneficial influence on atherosclerosis.

\section{Keywords:}




\section{Introduction}

Atherosclerosis is associated with significant cardiovascular morbidity and mortality. Characteristically, monocyte-derived macrophages and other leukocytes accumulate in the arterial intima in response to local lipoprotein retention. Here, immune activation and cell recruitment fuels an inflammatory state, in part by production of pro-inflammatory cytokines such as TNF, interleukin (IL)-1 $\beta$ and IL-12 (1, 2). Opposing these proinflammatory factors are select anti-inflammatory cytokines (e.g. IL-10) that support a more balanced plaque microenvironment. Since its involvement in human atherosclerosis was recognized $(3,4)$, a large body of evidence supports IL-10 as a potent regulator of several cellular processes central to plaque development. In plaques, this pleiotropic cytokine is produced by leukocytes, most notably macrophages (5), and acts to (auto)regulate pro-inflammatory cytokine synthesis (6-8). Furthermore, IL-10 influences foam cell formation (9) and promotes survival of immune cells $(3,10-13)$. As such, IL-10 signalling has been a target for selective intervention in experimental atherosclerosis. Indeed, several studies have employed either IL-10 gene therapy (11-13), or disruption of IL-10 (14-16) and its downstream signalling components $(17,18)$ to effectively consolidate its status as an atheroprotective cytokine.

As mentioned above, the combined actions of inflammatory responses and hyperlipidemia influence atherosclerosis. Maintaining cholesterol homeostasis is therefore of key importance (19). The liver is a central player here, adjusting synthesis and clearance of cholesterol and lipoproteins in relation to the supply of dietary cholesterol coming from the intestine. Additionally, the liver regulates removal of cholesterol from the body through high-density lipoprotein (HDL) mediated reverse cholesterol transport (RCT), for subsequent biliary secretion to the faeces. Although this hepatobiliary pathway was assumed to be the sole route for cholesterol excretion, several studies have now suggested the existence of an alternative pathway $(20,21)$. In addition to the liver, the intestine also profoundly affects cholesterol metabolism by facilitating cholesterol (re-)absorption, biosynthesis and faecal excretion. Recently, cholesterol transport from the blood to the intestinal lumen directly via enterocytes has been confirmed and termed transintestinal cholesterol efflux (TICE) (22). Although incompletely understood, available data illustrates that TICE contributes substantially to faecal neutral sterol (NS) excretion in rodents and also likely in humans $(23,24)$, with ApoB-containing lipoproteins, like VLDL and LDL, as cholesterol substrates (25). Hepatic depletion of acetylcoA-acetyltransferase 2 (ACAT2), the main enzyme responsible for the esterification of free cholesterol into ApoB-lipoproteins secreted by the liver, has been found to stimulate TICE (26). However, insight into the actual control mechanisms of TICE is limited.

So far, the way by which IL-10 influences atherosclerosis and cholesterol homeostasis is incompletely understood. For instance, it remains unclear which of IL-10's many target cell types mediate its beneficial atherosclerotic properties. Because myeloid responsiveness to $\mathrm{IL}-10$ is required for appropriate immunoregulation, we hypothesized that myeloid cells might be critical in IL-10-mediated modulation of plaque inflammation. Hence, we assessed the functional involvement of myeloid IL-10 signalling in atherogenesis. 
Our results reveal an unexpected pro-atherogenic role for myeloid IL-10R1 signalling in $\mathrm{LDLR}^{-/-}$mice, which is partly mediated through reduced hypercholesterolemia induced by altered intestinal cholesterol fluxes. Hereby, we identify a previously unknown connection between IL-10 signalling and intestinal cholesterol metabolism.

\section{Materials and Methods}

115

116

117

118

119

120

121

122

123

124

125

126

127

128

129

130

131

132

133

134

135

136

137

138

139

140

141

142

143

144

145

\section{Animals}

Mice carrying floxed IL-10R1 alleles (27) were crossed to LysMCre-mice (28) to yield animals with a homozygously floxed IL-10R1 gene and either wildtype or heterozygous knock-in for LysMCre (IL-10R1 ${ }^{\text {wt }}$ and IL$10 R 1^{\text {del }}$, respectively). These animals were backcrossed to $\mathrm{C} 57 \mathrm{Bl} / 6$ eight times. $\mathrm{LDLR}^{-/-}$mice were acquired from Jackson Laboratories (Bar Harbor, Maine, US) and had been backcrossed to C57BI/6 ten times. Female mice were used for atherosclerosis studies, since in our experience they display more robust lesion development in the aortic root than males. The Committee for Animal Welfare of Maastricht University Medical Center approved all study protocols (permit-nr. 2008-064 and 2010-167).

\section{Bone marrow transplantation}

SPF-housed female LDLR mice ${ }^{-/-}$were provided with water supplemented with neomycin (100 mg/l) and polymyxin B sulphate $\left(6 * 10^{4} \mathrm{U} / \mathrm{l}\right.$; both GIBCO, Breda, The Netherlands) one week prior to transplantation. Mice subsequently received 6 Gy total body irradiation on two consecutive days. $\mathrm{LDLR}^{-/-}$recipients received intravenous injection of $5^{*} 10^{6}$ pooled bone marrow cells from either IL-10R $1^{\text {wt }}$ mice or IL-10R1 ${ }^{\text {del }}$ donors (all littermates). Transplantation efficiency was evaluated ten weeks post-transplantation by isolating genomic DNA from blood leukocytes using the GFX Genomic Blood DNA purification kit (Amersham Pharmacia Biotech Inc., Arlington Heights, Illinois, USA) and the quantity of native (LDLR ${ }^{-1-}$ ) DNA was assessed using RT-qPCR, as previously described (15).

\section{Atherosclerosis assessment}

Following a six-week recovery period, $\mathrm{LDLR}^{-/-}$recipients were given a high-cholesterol diet (HCD) containing $16 \%$ fat, 0,15\% cholesterol and no cholate (Western type diet 4021.13, Hope Farms, The Netherlands) for 6 ( $n=9 /$ genotype) or 10 weeks ( $n=20 /$ genotype) to induce either early or more advanced atherosclerosis. At indicated time points over the course of each experiment fasting blood samples were collected for analyses as described below. Upon sacrifice, hearts were isolated, dissected and frozen in Tissue-Tek (Shandon, Veldhoven, The Netherlands). Subsequently, aortic roots were cut into $7 \mu \mathrm{m}$ sections, of which serial cryosections were routinely stained with toluidine blue for plaque quantification using Adobe Photoshop software. Moreover, plaques were classified by an experienced pathologist as early, moderate or advanced as described before (15).

\section{Immunohistochemistry}

Murine aortic root cryosections were fixed in acetone prior to incubation with antibodies against monocytes 
and macrophages (MOMA-2); newly recruited myeloid cells (ERMP-58, both from AbD Serotec, Uden, The Netherlands) and granulocytes (NIMP1 directed against Ly6G, BD Pharmingen, Breda, The Netherlands).

148 Staining was visualized using a biotin-labelled rabbit- $\alpha$-rat secondary antibody and ABC kit (Vector Labs, 149 Burlingame, CA, USA). Sirius red staining was performed to visualize plaque collagen content. Oil Red O (ORO) 150 staining enabled visualization of neutral lipids in plaques. TUNEL staining (Roche Diagnostics, Mannheim, 151 Germany) was used for detection of apoptotic cells. For MOMA-2, Sirius red and ORO staining, quantification 152 was performed using Adobe Photoshop software.

153 For intestinal immunohistochemistry, colons were excised upon sacrifice and paraffin-embedded. Then, $4 \mu \mathrm{m}$ sections were HE-stained and evaluated by an experienced pathologist.

155

\section{Flow cytometry analysis}

157 Absolute numbers of circulating leukocytes were determined by Trucount flow cytometry beads (BD 158 Biosciences, CA, USA). Leukocytes were defined as $\mathrm{CD} 45^{+}$, T-cells as $\mathrm{CD} 45^{+} \mathrm{CD}^{+} \mathrm{NK} 1.1^{-}$, NK-cells as $\mathrm{CD}_{4} 5^{+} \mathrm{CD} 3^{-}$ $159 \mathrm{NK} 1.1^{+}, \mathrm{NKT}$-cells as $\mathrm{CD} 45^{+} \mathrm{CD} 3^{\text {low }} \mathrm{NK} 1.1^{\text {low }}$, B-cells as CD45 ${ }^{+} \mathrm{CD} 3^{-} \mathrm{NK} 1.1^{-} \mathrm{B} 220^{+}$, granulocytes as CD45 ${ }^{+} \mathrm{CD} 3^{-} \mathrm{NK} 1.1^{-}$

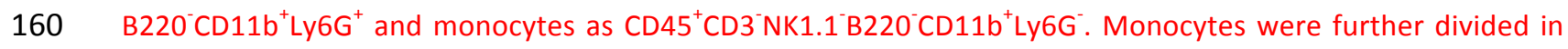
161 Ly6C $C^{\text {high }}$, Ly6C $C^{\text {low }}$ and Ly6C populations. Th-cells were defined as $C D 45^{+} \mathrm{CD}^{+} \mathrm{CD}^{+}$, while cytotoxic T-cells were $162 \mathrm{CD}^{2} 5^{+} \mathrm{CD}^{+} \mathrm{CD}^{+}$. An overview of antibodies is presented in supplementary Table SI. All FACS measurements were performed on a FACSCanto II with FACSDiva software (both BD Biosciences, CA, USA).

164 Plasma cytokine levels were measured by flow cytometry using a Cytometric Bead Array (BD Biosciences, CA, 165 USA) according to manufacturer's instructions.

166

\section{Primary macrophage culture}

168

Bone marrow cells were isolated from the hind limbs of wildtype and IL-10R1-deficient mice and cultured in RPMI-1640 medium (Life Technologies, Bleiswijk, The Netherlands) complemented with 10\% heat-inactivated foetal calf serum (Bodinco, Alkmaar, The Netherlands), $100 \mathrm{U} / \mathrm{ml}$ penicillin, $100 \mu \mathrm{g} / \mathrm{ml}$ streptomycin, $2 \mathrm{mM} \mathrm{L-}$ glutamine (all from GIBCO Invitrogen, Breda, The Netherlands) and 15\% L929-conditioned medium (LCM) for 89 days to generate bone marrow-derived macrophages (BMMs), as described previously (17). BMMs were seeded at $3.5 * 10^{5}$ cells/well in bacteriologic plastic 24-well plates (Greiner Bio-One, Alphen a/d Rijn, The

174 Netherlands) and incubated with $10 \mathrm{ng} / \mathrm{ml}$ of recombinant murine IL-10 (R\&D Systems Inc., Abingdon, UK) for

17524 hours or with $10 \mathrm{ng} / \mathrm{ml}$ LPS for 3,8 or 24 hours where designated.

\section{Gene expression} RNA was isolated from BMMs and liver samples using the High Pure RNA Isolation Kit (Roche, Woerden, The 179 Netherlands). RNA isolation from aortic arches was performed using the RNeasy mini column kit (Qiagen, 180 Venlo, The Netherlands). $500 \mathrm{ng}$ total RNA was reverse transcribed using the iScript cDNA Synthesis Kit (BioRad, 181 Veenendaal, The Netherlands). Quantitative PCR (qPCR) was performed using $10 \mathrm{ng}$ cDNA, $300 \mathrm{nM}$ of each 
primer, and sensiMix SYBR Hi-ROX (Bioline, Brussels, Belgium) in a total volume of $20 \mu$ l. Gene expression levels were corrected for cyclophilin A as reference gene. Primer sequences are available upon request.

RT2 Profiler ${ }^{\mathrm{TM}}$ PCR Array Mouse Lipoprotein Signaling \& Cholesterol Metabolism (PAMM-080Z, Qiagen, Venlo, The Netherlands) was used to outline cholesterol-associated gene expression in RNA from homogenized liver samples according to manufacturer's protocols ( $n=8 /$ genotype).

\section{Cytokine secretion}

TNF and IL-12 secretion by IL-10R $1^{\text {wt }}$ and IL-10R $1^{\text {del }}$ BMMs was quantified in supernatants after LPS stimulation using corresponding ELISA kits (Invitrogen, Bleiswijk, The Netherlands) according to manufacturer's protocols.

\section{Macrophage apoptosis and efferocytosis assay}

BMMs were seeded at $1 * 10^{5}$ cells/well in bacteriologic plastic 96-well plates (Greiner Bio-One, Alphen a/d Rijn, The Netherlands). BMMs were treated for 22 hours with $10 \mathrm{ng} / \mathrm{ml}$ recombinant murine IL-10 (R\&D Systems Inc., Abingdon, UK) or left untreated. Hereafter, both medium and cells were collected and double stained with Annexin $\mathrm{V}$ and propidium iodide (both eBioscience, Vienna, Austria) for 15 minutes at room temperature. Apoptosis was then assessed by flow cytometry. The percentage of dead cells was defined as the sum of Annexin $\mathrm{V}^{+} / \mathrm{PI}^{+}$and Annexin $\mathrm{V}^{-} / \mathrm{PI}^{+}$cells.

To assess efferocytosis, BMMs were incubated with $5 * 10^{5}$ apoptotic Dil-labeled (Life Technologies, Bleiswijk, The Netherlands) RAW264.7 cells for 1 hour. Efferocytosis was assessed by flow cytometry after residual apoptotic cells were washed away.

\section{Macrophage oxLDL loading}

BMMs, left untreated or treated for 24 hours with $10 \mathrm{ng} / \mathrm{ml} \mathrm{IL-10} \mathrm{were} \mathrm{incubated} \mathrm{for} 3$ hours in Optimem-1 with $12.5 \mathrm{mg} / \mathrm{ml}$ Dil-labelled oxLDL (SanBio, Uden, The Netherlands). Uptake was assessed by flow cytometry after residual oxLDL was washed away.

\section{Lipid analysis}

Total plasma cholesterol and triglyceride levels were determined using standard enzymatic kits according to manufacturer's protocols (Sigma-Aldrich, Zwijndrecht, The Netherlands).

For liver cholesterol and triglyceride quantification, frozen liver specimens were homogenized in $1.0 \mathrm{ml}$ SET buffer (Sucrose $250 \mathrm{mM}$, EDTA $2 \mathrm{mM}$ and Tris $10 \mathrm{mM}$ ) using $5.0 \mathrm{~mm}$ glass beads. Three freeze-thaw cycles ensured complete cell lysis. Liver protein content was measured using the BCA method (Pierce, Rockford, IL, USA). Lipid measurements were performed as described above. Lipoprotein profiles were determined on pooled plasma samples from 20 mice/genotype using an AKTA Basic chromatography system with a Superose 6PC 3.2/30 column (Amersham Biosciences, Roosendaal, The Netherlands). 
220 Cholesterol fluxes were measured as described previously (29). Briefly, at day 0, mice received an intravenous dose of $0.3 \mathrm{mg}(0.73 \mu \mathrm{mol})$ cholesterol- $\mathrm{D}_{7}$ dissolved in Intralipid (20\%, Fresenius Kabi, Den Bosch, The Netherlands) and an oral dose of $0.6 \mathrm{mg}(1.535 \mu \mathrm{mol})$ cholesterol- $\mathrm{D}_{5}$ dissolved in medium-chain triglyceride oil. Blood spots were collected from the tail on filter paper (Schleicher \& Schuell No2992, 's Hertogenbosch, The Netherlands) daily for 10 days. 72 hours before sacrifice ${ }^{13} \mathrm{C}$-acetate was added to the drinking water to determine the amount of newly synthesized cholesterol. At the end of the experiment, mice were anaesthetised (intraperitoneal Ketamine/Diazepam), the gallbladder was canulated and bile was collected for 30 minutes. Subsequently, mice were sacrificed by cardiac puncture and organs were harvested. Feces were collected for 48 hours prior to sacrifice. For analytical procedures, cholesterol was extracted from blood spots and cholesterol- $D_{5}$ and $D_{7}$ were analysed by gas chromatography/mass spectrometry (GC/MS) as described (30). Biliary phospholipid concentrations were determined as described (30). Biliary bile acids were determined by an enzymatic fluorimetric assay. Cholesterol in plasma and bile, faecal cholesterol and its derivatives (also called neutral sterols) and biliary bile acid species were determined by gas chromatography (30). Hepatic lipids were extracted according to Bligh \& Dyer.

\section{Cholesterol precursor analysis}

Cholesterol was determined by gas chromatography-flame ionization detection using 5a-cholestane as internal standard. The cholesterol precursors lathosterol, lanosterol and desmosterol as well as the plant sterol campesterol were measured by gas chromatography-mass spectrometry-selected ion monitoring, as described previously $(31,32)$.

241

\section{Statistics}

243 Data are presented as mean \pm the standard error of the mean (SEM). All statistical analyses were performed using GraphPad Prism (GraphPad Software Inc.). Groups were compared using (Welch-corrected) two-tailed, non-paired t-tests or a two-way ANOVA. Plaque severity scores were compared using a Chi-square test. Significance was set at $\mathrm{p}<0.05$. $^{*} * *$ and $* * *$ indicate $\mathrm{p}<0.05,0.01$ and 0.001 , respectively.

\section{Results}

\section{IL-10R1 ${ }^{\text {del }}$ primary macrophages are unresponsive to IL-10 and hyperresponsive to LPS}

250 To assess macrophage function in absence of IL-10R signalling, we specifically deleted IL-10R1 in the myeloid 251 lineage by crossing IL-10R1 ${ }^{\text {floxed }}$ mice with LysMCre mice. The resulting LysMCre-IL-10R1 $1^{\mathrm{fl} / \mathrm{fl}}$ (IL-10R1 ${ }^{\mathrm{del}}$ ) mice 252 were compared to $\mathrm{IL}-10 \mathrm{R} 1^{\mathrm{fl} / \mathrm{fl}}\left(\mathrm{IL}-10 \mathrm{R} 1^{\mathrm{wt}}\right)$ mice as wildtype controls. Deletion in bone marrow-derived macrophages (BMMs) resulted in an approximate 80\% decrease in IL10R1 gene expression (Figure S1A, further characterization has been described in (27)). This significantly impaired induction of established IL-10 target genes (e.g. suppressor of cytokine signalling 3, SOCS3; IL-4R $\alpha$ ) upon IL-10 treatment (Figure S1B, S1C), 
indicating that genetic ablation of IL-10R1 was both efficient and effective. As IL-10 is an important regulator of innate pathogen-associated inflammation, we tested the response to lipopolysaccharide (LPS). After 24 hours LPS stimulation, IL-10R1 ${ }^{\text {del }}$ BMMs showed enhanced secretion of pro-inflammatory cytokines TNF and IL-12p40 in comparison to WT BMMs (Figure S1D, S1E). Moreover, whereas IL-10 treatment could strongly inhibit these cytokine responses in WT BMMs, this effect was far less pronounced in IL-10R1 ${ }^{\text {del }}$ BMMs (Figure S1F-S1G). Thus, IL-10R $1^{\text {del }}$ macrophages have a pro-inflammatory phenotype in vitro.

Myeloid IL-10R1-deficiency attenuates atherosclerotic plaque size and severity in $\mathrm{LDLR}^{-/-}$mice and promotes apoptosis

Next, we examined the involvement of myeloid IL-10R1 signalling in atherosclerosis development. To this end, we reconstituted lethally irradiated $\mathrm{LDLR}^{-/}$mice with bone marrow from either IL-1OR1 ${ }^{\mathrm{wt}}$ or IL-10R1 $1^{\mathrm{del}}$ mice. Repopulation of the bone marrow compartment was found to be similar for both groups ( $97.6 \% \pm 0.1$ vs. $97.1 \%$ \pm 0.3 ). After 10 weeks of high cholesterol diet (HCD), quantification of atherosclerosis in the aortic root revealed a dramatic $70 \%$ reduction in lesion area in IL-10R1 ${ }^{\text {del }}$ mice vs. IL-10R ${ }^{\text {wt }}$ animals (Figure $1 \mathrm{~A}$ and $1 \mathrm{~B}$ ). Moreover, classification of plaque severity showed that lesions from IL-1OR1 ${ }^{\text {del }}$ mice were less advanced in comparison to their wildtype counterparts (Figure $1 \mathrm{C}$, Chi-square test $p<0.0001$ ). Quantification of plaque collagen area demonstrated that lesions from IL-10R1-deficient animals had 34\% less fibrous tissue in relation to lesion size as compared to controls (Figure 1D).

In order to confirm the consistency of the overall phenotype, we performed an analogous experiment with a six-week period of high cholesterol feeding. Again, IL-10R1 ${ }^{\text {del }}$ mice demonstrated a $70 \%$ decrease in plaque area as compared to wildtype animals (Figure S3A and S3B). Together, these findings indicate that disruption of myeloid IL-10R signalling strongly inhibits atherosclerosis development.

As apoptosis and efferocytosis are important modifiers of atherogenesis and macrophages account for most of the apoptotic cells in plaques $(33,34)$, we investigated TUNEL $^{+}$cell count in atherosclerotic lesions. This revealed a significantly higher incidence of apoptotic cells $/ \mathrm{mm}^{2}$ in lesions from IL-10R1 ${ }^{\text {del }}$ mice (Figure 1E). Going on, we sought to validate this finding in vitro by examining whether survival of IL-10R ${ }^{\text {del }}$ BMMs differs from their wildtype counterparts. Indeed, in unstimulated conditions we found IL-10R ${ }^{\text {del }}$ BMMs intrinsically display a higher degree of apoptosis (Figure S2A). This susceptibility was made more apparent by additional IL10 treatment, which protected wildtype but not IL-10R deficient macrophages from apoptotic cell death (Figure S2A). Yet, the increased apoptotic cell count in plaques could not be explained by reduced efferocytosis of apoptotic cells, as absence of IL-10 signalling did not affect efferocytosis of apoptotic RAW cells by BMMs (Figure S2B).

\section{Myeloid IL-10R1 deficiency reduces plaque neutral lipid content and macrophage cholesterol loading}

Because hyperlipidemia is a driving force of atherosclerosis, we explored circulating lipid levels in both groups of mice. Whilst bodyweight and plasma triglyceride content were equal between genotypes, plasma cholesterol was markedly reduced in IL-10R1-deficient animals (Table 1). This effect was greatest after 10 
weeks HCD, but already apparent on chow diet. We questioned whether this resistance to diet-induced hypercholesterolemia in IL-10R $1^{\text {del }}$ mice affected plaque size and morphology. Through linear regression analysis of plasma cholesterol levels and plaque size we observed that the generated curves had different slopes, indicating that for given cholesterol levels IL-10R1-deficient plaques were smaller (Figure S4A). To confirm this, we selected mice with comparable cholesterol exposure (Figure S4B) and found that in absence of myeloid IL-10R1-signalling plaque burden was still significantly decreased (Figure S4C). Thus, reduced blood cholesterol levels could not fully account for altered lesion size in these animals. As IL-10 is known to influence macrophage cholesterol handling (9), we quantified plaque neutral lipid content by Oil Red O (ORO) staining. This revealed a significantly reduced $\mathrm{ORO}^{+}$area in relation to plaque size in IL$10 R 1^{\text {del }}$ mice (Figure $1 F$ and $1 G$ ), suggesting diminished foam cell formation in vivo. We subsequently confirmed this finding in vitro, as IL-10R $1^{\text {del }}$ BMMs displayed significantly less oxLDL uptake compared to IL-10R $1^{\text {wt }} B M M s$ upon 3 hours of oxLDL incubation (Figure $1 \mathrm{H}$ and $1 \mathrm{I}$ ). This effect could be abolished in wildtype BMMs by a neutralizing $\alpha-\mathrm{IL}-10$ antibody, whereas uptake by IL-10R1 ${ }^{\text {del }}$ BMMs was not affected (Figure $1 \mathrm{H}$ ). This effect was associated with decreased transcription of the scavenger receptors CD36 and SR-A, as well as efflux transporters $A B C A 1$ and $A B C G 1$, which were shown previously to be IL-10-inducible genes. (Figure $1 \mathrm{~J}$ and $1 \mathrm{~K}$ ) $(9,35)$. Concluding, myeloid IL-10R1 deletion instigates resistance to macrophage cholesterol loading.

Myeloid IL-10R1 deficiency limits plaque macrophage and neutrophil content, but does not affect systemic inflammation

312 Since IL-10 limits the inflammatory responses that drive plaque progression, we tested whether myeloid IL313 10R1-deficiency affected systemic and intimal inflammation in our atherosclerosis model. Focussing first on 314 absolute blood leukocyte counts, we found no differences in circulating monocyte subsets or granulocytes after 3156 weeks of HCD, whereas in the lymphoid compartment only a mild increase in NKT-cells was observed (Table 316 SII). Similarly, plasma levels of inflammatory cytokines were comparable between genotypes (Figure 2A). 317 Hence, in contrast to our in vitro data, we have no evidence to indicate that loss of myeloid IL-10 signalling 318 leads to systemically enhanced inflammation in an atherosclerotic setting.

319 Going on to assess the inflammatory status of the vessel wall, we first evaluated inflammatory gene expression in the aortic arch. In reflection of impaired atherogenesis in IL-10R1 ${ }^{\text {del }}$ mice, we noted decreased aortic 321 expression of the macrophage marker CD68 (Figure 2B). Myeloid IL-10R1 disruption, however, did not elicit a 322 significantly skewed inflammatory profile (Figure 2C). Subsequently, we measured plaque leukocyte content. 323 Unsurprisingly, lesions consisted mostly of macrophages, which were significantly less numerable in IL-10R $1^{\text {del }}$ 324 plaques (Figure 2D and 2E). The number of newly recruited myeloid cells was also smaller in IL-10R1 ${ }^{\text {del }}$ lesions 325 after 6 weeks and 10 weeks of HCD (Figure 2F and 2G). Neutrophil counts were only significantly diminished in $326 \mathrm{IL}-10 \mathrm{R} 1^{\text {del }}$ mice at 6 weeks of HCD (Figure $2 \mathrm{H}$ and 2I). Although these data indicate reduced recruitment of 327 monocytes/macrophages towards the atherosclerotic lesion in IL-10R1 ${ }^{\text {del }}$ mice, we found no changes in aortic 328 chemokine/adhesion molecule expression or macrophage adhesive capacity (using in vitro static adhesion of 
Myeloid IL-10R1 deficiency reduces hypercholesterolemia in high cholesterol fed LDLR $^{-/}$mice

Encouraged by diminished plasma cholesterol levels in myeloid IL-10R1 deficiency, we further investigated cholesterol metabolism in these mice. We first wanted to rule out enterocolitis as a cause of reduced hypercholesterolemia, as disruption of IL-10 signalling can predispose to inflammatory bowel disease (IBD) (3639). As genetic background and environmental factors influence disease course (40), we used SPF mice on a naturally resistant C57BI/6 background, ensuring our colony tested negative for Helicobacter pylori (data not shown). Under these conditions, IL-10R1 ${ }^{\text {del }}$ mice did not present with weight loss (Figure S5A) or any other symptoms to suggest IBD. Moreover, histological examination of colonic tissue revealed no overt intestinal inflammation in IL-10R ${ }^{\text {del }}$ mice (Figure S5B).

To gain further insight into the observed cholesterol phenotype, we subsequently assessed lipoprotein profiles in pooled plasma samples taken before and 10 weeks after HCD. IL-10R1 ${ }^{\text {del }}$ mice showed a pronounced $56.3 \%$ and $33.6 \%$ decrease in circulating VLDL and LDL particles respectively upon HCD, whereas no differences in HDL cholesterol were observed (Figure $3 \mathrm{~A}$ and $3 \mathrm{~B}$ ). Liver total cholesterol levels mirrored those in plasma, while triglyceride levels remained similar between both groups of mice (Figure $3 C$ ).

Next, to evaluate which areas of cholesterol metabolism were affected by loss of myeloid IL-10 signalling, we performed a $\mathrm{RT}^{2}$ Profiler ${ }^{\mathrm{TM}} \mathrm{PCR}$ Array aimed at genes involved in lipoprotein signalling and cholesterol metabolism on hepatic RNA. Out of 84 genes, 9 genes were significantly upregulated in IL-10R1 ${ }^{\text {del }}$ mice compared to IL-10R1 ${ }^{\text {wt }}$ (Figure 3D). Together, these genes represent the majority of enzymes involved in the cholesterol biosynthesis cascade, indicating enhanced endogenous cholesterol synthesis. In addition, 13 genes involved in cellular cholesterol transport and metabolism displayed significant downregulation (Figure 3D). We subsequently determined the plasma lathosterol-to-cholesterol ratio, a marker of de novo cholesterol synthesis rate (19). Surprisingly, we found this ratio to be decreased by $11,8 \%$ in IL-10R $1^{\text {del }}$ mice relative to controls. However, lanosterol (the principal precursor of lathosterol) and desmosterol did match hepatic gene expression in showing significantly enhanced plasma levels in IL-10R1 ${ }^{\text {del }}$ mice (by $85.6 \%$ and $44.5 \%$ respectively) (Figure 3E). Thus, increased cholesterol biosynthesis was unlikely to account for reduced hypercholesterolemia in IL-10R1 ${ }^{\text {del }}$ mice. We then shifted our focus toward plasma markers of intestinal cholesterol absorption

358 (campesterol and cholestenol), as the amount of dietary cholesterol directed to the liver by the intestine strongly affects cholesterol synthesis rates (19). Both of these markers showed lower plasma levels in relation to cholesterol in IL-10R1 ${ }^{\text {del }}$ mice (a decrease of 24.9 and $11.6 \%$ respectively) (Figure 3F), implying reduced intestinal absorption of cholesterol is a likely contributor to reduced hypercholesterolemia and increased cholesterol biosynthesis in IL-10R1 ${ }^{\text {del }}$ mice. 
In addition to de novo cholesterol synthesis and intestinal absorption, excretion of cholesterol into faeces is another key determinant of cholesterol homeostasis. Traditionally occurring through hepatobiliary excretion, recently a distinct transintestinal route of cholesterol excretion (TICE) has come under attention that operates independently from the biliary pathway. We quantified these cholesterol fluxes using differentially labelled cholesterol molecules and ${ }^{13} \mathrm{C}$-acetate. Basal characteristics of IL-1OR1 ${ }^{\mathrm{wt}}$ and IL-1OR1 ${ }^{\mathrm{del}}$ mice before and after 6 weeks HCD are shown in Table 2. IL-10R ${ }^{\text {del }}$ mice demonstrated decreased plasma and liver cholesterol levels, whereas liver triglyceride levels were equal between genotypes. Likewise, hepatobiliary output parameters did not reveal any differences between both groups of mice (Table 3). In line with hepatic gene expression, the level of newly synthesized cholesterol in IL-10R1 ${ }^{\text {del }}$ mice was increased 375 five-fold compared to wildtype animals (Figure 4A). This coincided with significantly enhanced mRNA levels for 376 HMG-COA reductase in liver and intestine of IL-10R1 ${ }^{\text {del }}$ mice (Figure 4B). Fractional intestinal absorption of cholesterol was indeed lowered in myeloid IL-10R deficiency (Figure 4C). Next, we assessed the amount of faecal sterol loss. IL-10R1 ${ }^{\text {del }}$ mice showed a pronounced increase in faecal neutral sterol (NS) and cholesterol content (Figure 4D). Yet, the amount of faecal bile acids was comparable between genotypes (Figure 4D). Interestingly, linear regression analysis revealed an inverse correlation between plasma cholesterol levels and faecal neutral sterol content in IL-10R1 ${ }^{\text {del }}$ mice, but not in wildtype animals (Figure 4E). By integrating calculated cholesterol fluxes, we defined the amount of non-biliary cholesterol efflux (TICE) in IL-10R1 ${ }^{\text {del }}$ and IL-10R1 ${ }^{\text {wt }}$ mice. In line with our previous finding, non-biliary cholesterol efflux was upregulated almost 12 -fold in the absence of myeloid IL-10R signalling (Figure 4F). Notably, an inverse link between TICE and the expression of Cyp7A1 and Cyp8B1 enzymes was demonstrated recently (unpublished data A.K.G.). Consequently, we determined hepatic gene expression of these bile acid synthesizing enzymes and found them to be significantly downregulated in IL-10R1 ${ }^{\text {del }}$ mice (Figure 4G). In summary, decreased hypercholesterolemia in these animals exists by virtue of reduced fractional absorption of cholesterol and enhanced non-biliary faecal cholesterol excretion.

Enhanced non-biliary cholesterol efflux in myeloid IL-10R1 deficient mice is associated with decreased ACAT2 expression and function Recent data shows that hepatic depletion of ACAT2, an enzyme responsible for cholesterol esterification, enhances TICE. This suggests that VLDL and LDL composition, which are likely substrates for TICE, can directly influence TICE activity $(25,26)$. We therefore analysed cholesteryl ester (CE) and free cholesterol (FC) content of plasma and hepatic lipoprotein particles, which revealed a significantly reduced CE/FC ratio in IL-1OR1 ${ }^{\text {del }}$ mice when compared to controls (Figure 5A and 5B). Furthermore, we evaluated gene expression of ACAT2 in BMMs upon 24 hours of IL-10 stimulation, confirming ACAT2 is an IL-10-inducible gene (Figure 5C). Hepatic expression of ACAT2 in IL-10R1 ${ }^{\text {del }}$ mice was significantly reduced (Figure 5D), while intestinal mRNA levels were comparable between genotypes. However, ACAT2 gene expression in the proximal small intestine did inversely 
expression and function are impaired in absence of myeloid IL-10R1 signalling, which may contribute to the altered cholesterol metabolism in IL-10R $1^{\text {del }}$ mice.

\section{Discussion}

Despite previous reports demonstrating the anti-atherogenic properties of IL-10, the specific cell types responsible for IL-10's atheroprotective effects remained to be defined. We used hyperlipidemic mice carrying a conditional deletion of the ligand-binding domain of the IL-10 receptor complex (i.e. IL-10R1) in their myeloid lineage to assess whether myeloid cells form the basis of IL-10-mediated atheroprotection.

IL-10's ability to negatively regulate macrophage activation was recognized soon after its discovery in 1989 (6, 7). Comparably, our current in vitro findings demonstrate that BMMs deficient for IL-1OR1 lose most of their responsiveness to IL-10 and consequently are less well equipped to dampen TLR4-mediated activation in vitro. Thereby, we strengthen the observations by Pils et al. (27), who demonstrated the pro-inflammatory nature of the IL-10R1 ${ }^{\text {del }}$ phenotype in an experimental LPS endotoxemia model. Whereas prior evidence demonstrates a robust and consistent decrease in atherosclerosis development and associated inflammation by enhancing local or systemic IL-10 levels $(3,11,12)$, haematopoietic $(16)$ or systemic $(14,41)$ deficiency for this cytokine typically yields increased plaque formation. In this light, we expected IL-10R1 ${ }^{\text {del }}$ mice to display increased inflammation and atherogenesis. Instead, we observed that loss of myeloid IL-10R1 signalling attenuates atherosclerotic lesion size and severity through altered susceptibility to diet-induced hypercholesterolemia, reduced lesional leukocyte accumulation and enhanced apoptosis. If anything, this suggests IL-10 exerts diverse cell-specific effects in atherogenesis and cholesterol handling that act as important determinants of disease outcome.

Even though IL-10R1 ${ }^{\text {del }}$ BMMs displayed greater inflammatory potential in vitro, we consider the lack of amplified systemic inflammation in IL-10R1 ${ }^{\text {del }}$ mice a reflection of the complexity that comes with cell-cell interactions under hyperlipidemic conditions. As myeloid IL-10 signalling is dispensable with regard to counteracting pro-inflammatory mediators in the atherosclerotic vessel wall, other cell types are likely to facilitate IL-10-mediated atheroprotection. Endothelial cells could for instance act as an influential player in IL10-mediated immunomodulation. Aside from the fact that IL-10 can favourably affect endothelial cell function $(42,43)$, work by us and others has revealed contrasting outcomes when using macrophage and endothelial cell-specific approaches to interfere with inflammatory signalling pathways $(15,44)$. In this context, some have argued that a dichotomy between pro- and anti-inflammatory cytokines is too simplistic and that a given cytokine may behave in either way depending on multiple variables. In addition, there have been several reports demonstrating an unfavourable role for IL-10 in inflammatory disease, explaining why IL-10 treatment regimes in for instance inflammatory bowel disease have yielded somewhat disappointing results (45).

Lipid metabolism has a central role in the pathogenesis of atherosclerosis and it is known that lipid metabolism and inflammatory processes can interact on many levels to influence atherogenesis (46). Previous reports concerning IL-10 overexpression in experimental atherosclerosis have reported an average decrease in plasma cholesterol levels of approximately $50 \%(13,47)$. Contrastingly, our data reveal a substantial reduction in 
plasma cholesterol levels in mice with abrogated myeloid IL-10 signalling, which was also reflected in the lesional neutral lipid content. We could associate this decreased hypercholesterolemia with lowered VLDL and LDL levels upon altered intestinal cholesterol fluxes. We found a sizeable decrease in intestinal cholesterol absorption with compensatory stimulation of hepatic and intestinal cholesterol biosynthesis. Moreover, while hepatobiliary output was unchanged between genotypes, IL-10R1 ${ }^{\text {del }}$ mice demonstrated substantially higher levels of faecal sterol loss. Accordingly, augmented non-biliary cholesterol efflux in these mice was linked to impaired ACAT2-mediated esterification of liver and plasma cholesterol, as well as decreased expression of bile acid synthesis genes Cyp7A1 and Cyp8B1. This non-biliary cholesterol route, or TICE, has gained attention over the past few years and several mouse models now provide evidence for this alternate pathway of RCT facilitated by the intestine (22). Yet, the exact processes that regulate TICE remain subject of investigation. Since intestinal cholesterol output is likely to be derived from plasma lipoproteins synthesized by the liver, we expect the liver to exert a certain amount of control regarding TICE. Interestingly, Brown et al. (26) recently reported on a model of liver-specific depletion of ACAT2, in which it was shown that limited hepatic cholesterol esterification leads to decreased levels of plasma VLDL, LDL and total liver cholesterol, while leaving plasma HDL unaltered. Moreover, fractional intestinal absorption of cholesterol was reduced in hepatic ACAT2 depleted mice, whereas faecal neutral sterol excretion was increased. This phenotype bears many striking similarities to that of IL-10R1 ${ }^{\text {del }}$ mice, which possess a pronounced decline in CE/FC ratio and a significant reduction in hepatic ACAT2 gene expression, suggestive of impaired function. In support of this notion, macrophages incubated in vitro with IL-10 and acLDL were previously shown to accumulate more cholesterol esters than cells treated with acLDL alone (9).

459 In summary, abrogating myeloid IL-10 signalling strongly reduces plaque development in atherogenic LDLR ${ }^{-1-}$ mice by compromising recruitment and survival of myeloid cells in atherosclerotic lesions and by mediating resistance to diet-induced hyperlipidemia. Hence, myeloid cells are not responsible for IL-10-mediated atheroprotection. Ultimately, this means that IL-10's functional involvement in atherosclerosis is less straightforward, inducing opposing effects in target cell types and thereby challenging us to re-examine our view of IL-10 as a beneficial influence on atherosclerosis. In addition, this study is the first to demonstrate that ablation of myeloid IL-10 signalling affects the packaging of cholesterol into nascent lipoproteins by ACAT2, limits intestinal cholesterol absorption and enhances non-biliary cholesterol efflux. More research directed at this novel connection between IL-10 and cholesterol homeostasis is needed to develop a more thorough understanding of IL-10's therapeutic potential in chronic inflammatory diseases, including atherosclerosis.

469

\section{Acknowledgements}

471 None 
$474 \quad 1 . \quad$ Galkina E, Ley K. Immune and inflammatory mechanisms of atherosclerosis (*). Annual review of immunology. 2009;27:165-97.

$4762 . \quad$ Hansson GK, Libby P. The immune response in atherosclerosis: a double-edged sword. Nature reviews

477 Immunology. 2006;6(7):508-19.

478 3. Han X, Kitamoto S, Wang H, Boisvert WA. Interleukin-10 overexpression in macrophages suppresses

479 atherosclerosis in hyperlipidemic mice. FASEB journal : official publication of the Federation of American

480 Societies for Experimental Biology. 2010;24(8):2869-80.

481 4. Mallat Z, Heymes C, Ohan J, Faggin E, Leseche G, Tedgui A. Expression of interleukin-10 in advanced Arteriosclerosis, thrombosis, and vascular biology. 1999;19(3):611-6.

5. Kleemann R, Zadelaar S, Kooistra T. Cytokines and atherosclerosis: a comprehensive review of studies in mice. Cardiovascular research. 2008;79(3):360-76.

6. de Waal Malefyt R, Abrams J, Bennett B, Figdor CG, de Vries JE. Interleukin 10(IL-10) inhibits cytokine synthesis by human monocytes: an autoregulatory role of IL-10 produced by monocytes. The Journal of experimental medicine. 1991;174(5):1209-20.

7. Fiorentino DF, Zlotnik A, Mosmann TR, Howard M, O'Garra A. IL-10 inhibits cytokine production by activated macrophages. Journal of immunology. 1991;147(11):3815-22.

8. Moore KW, de Waal Malefyt R, Coffman RL, O'Garra A. Interleukin-10 and the interleukin-10 receptor. Annual review of immunology. 2001;19:683-765.

9. Han X, Kitamoto S, Lian Q, Boisvert WA. Interleukin-10 facilitates both cholesterol uptake and efflux in macrophages. The Journal of biological chemistry. 2009;284(47):32950-8.

10. Halvorsen B, Waehre T, Scholz H, Clausen OP, von der Thusen JH, Muller F, et al. Interleukin-10 enhances the oxidized LDL-induced foam cell formation of macrophages by antiapoptotic mechanisms. Journal of lipid research. 2005;46(2):211-9.

11. Namiki M, Kawashima S, Yamashita T, Ozaki M, Sakoda T, Inoue N, et al. Intramuscular gene transfer of interleukin-10 cDNA reduces atherosclerosis in apolipoprotein E-knockout mice. Atherosclerosis. 2004;172(1):21-9.

12. Pinderski LJ, Fischbein MP, Subbanagounder G, Fishbein MC, Kubo N, Cheroutre H, et al. Overexpression of interleukin-10 by activated T lymphocytes inhibits atherosclerosis in LDL receptor-deficient Mice by altering lymphocyte and macrophage phenotypes. Circulation research. 2002;90(10):1064-71. 13. Von Der Thusen JH, Kuiper J, Fekkes ML, De Vos P, Van Berkel TJ, Biessen EA. Attenuation of atherogenesis by systemic and local adenovirus-mediated gene transfer of interleukin-10 in LDLr-/- mice. FASEB journal : official publication of the Federation of American Societies for Experimental Biology. 2001;15(14):2730-2.

14. Caligiuri G, Rudling M, Ollivier V, Jacob MP, Michel JB, Hansson GK, et al. Interleukin-10 deficiency increases atherosclerosis, thrombosis, and low-density lipoproteins in apolipoprotein E knockout mice. Molecular medicine. 2003;9(1-2):10-7.

15. Kanters E, Pasparakis M, Gijbels MJ, Vergouwe MN, Partouns-Hendriks I, Fijneman RJ, et al. Inhibition of NF-kappaB activation in macrophages increases atherosclerosis in LDL receptor-deficient mice. The Journal of clinical investigation. 2003;112(8):1176-85.

16. Potteaux S, Esposito B, van Oostrom O, Brun V, Ardouin P, Groux H, et al. Leukocyte-derived interleukin 10 is required for protection against atherosclerosis in low-density lipoprotein receptor knockout mice. Arteriosclerosis, thrombosis, and vascular biology. 2004;24(8):1474-8.

17. Kanters E, Gijbels MJ, van der Made I, Vergouwe MN, Heeringa P, Kraal G, et al. Hematopoietic NFkappaB1 deficiency results in small atherosclerotic lesions with an inflammatory phenotype. Blood. 2004;103(3):934-40.

18. Khan JA, Cao M, Kang BY, Liu Y, Mehta JL, Hermonat PL. AAV/hSTAT3-gene delivery lowers aortic inflammatory cell infiltration in LDLR KO mice on high cholesterol. Atherosclerosis. 2010;213(1):59-66. 19. van der Wulp MY, Verkade HJ, Groen AK. Regulation of cholesterol homeostasis. Molecular and cellular endocrinology. 2013;368(1-2):1-16.

20. Cheng SH, Stanley MM. Secretion of cholesterol by intestinal mucosa in patients with complete common bile duct obstruction. Proceedings of the Society for Experimental Biology and Medicine Society for Experimental Biology and Medicine. 1959;101(2):223-5. 
21. Kruit JK, Plosch T, Havinga R, Boverhof R, Groot PH, Groen AK, et al. Increased fecal neutral sterol loss upon liver $\mathrm{X}$ receptor activation is independent of biliary sterol secretion in mice. Gastroenterology. 2005;128(1):147-56.

22. van der Velde AE, Brufau G, Groen AK. Transintestinal cholesterol efflux. Current opinion in lipidology. 2010;21(3):167-71.

23. Le May C, Berger JM, Lespine A, Pillot B, Prieur X, Letessier E, et al. Transintestinal cholesterol excretion is an active metabolic process modulated by PCSK9 and statin involving ABCB1. Arteriosclerosis, thrombosis, and vascular biology. 2013;33(7):1484-93.

24. van der Velde AE, Vrins CL, van den Oever K, Kunne C, Oude Elferink RP, Kuipers F, et al. Direct intestinal cholesterol secretion contributes significantly to total fecal neutral sterol excretion in mice. Gastroenterology. 2007;133(3):967-75.

25. Vrins CL, Ottenhoff R, van den Oever K, de Waart DR, Kruyt JK, Zhao Y, et al. Trans-intestinal cholesterol efflux is not mediated through high density lipoprotein. Journal of lipid research. 2012;53(10):201723.

26. Brown JM, Bell TA, 3rd, Alger HM, Sawyer JK, Smith TL, Kelley K, et al. Targeted depletion of hepatic ACAT2-driven cholesterol esterification reveals a non-biliary route for fecal neutral sterol loss. The Journal of biological chemistry. 2008;283(16):10522-34.

27. Pils MC, Pisano F, Fasnacht N, Heinrich JM, Groebe L, Schippers A, et al. Monocytes/macrophages and/or neutrophils are the target of IL-10 in the LPS endotoxemia model. European journal of immunology. 2010;40(2):443-8.

28. Clausen BE, Burkhardt C, Reith W, Renkawitz R, Forster I. Conditional gene targeting in macrophages and granulocytes using LysMcre mice. Transgenic research. 1999;8(4):265-77.

29. Brufau G, Kuipers F, Lin Y, Trautwein EA, Groen AK. A reappraisal of the mechanism by which plant sterols promote neutral sterol loss in mice. PloS one. 2011;6(6):e21576.

30. van der Veen JN, van Dijk TH, Vrins CL, van Meer H, Havinga R, Bijsterveld K, et al. Activation of the liver $\mathrm{X}$ receptor stimulates trans-intestinal excretion of plasma cholesterol. The Journal of biological chemistry. 2009;284(29):19211-9.

31. Lutjohann D, Brzezinka A, Barth E, Abramowski D, Staufenbiel M, von Bergmann K, et al. Profile of cholesterol-related sterols in aged amyloid precursor protein transgenic mouse brain. Journal of lipid research. 2002;43(7):1078-85.

32. Sudhop T, Lutjohann D, Kodal A, Igel M, Tribble DL, Shah S, et al. Inhibition of intestinal cholesterol absorption by ezetimibe in humans. Circulation. 2002;106(15):1943-8.

33. Tabas I. Macrophage apoptosis in atherosclerosis: consequences on plaque progression and the role of endoplasmic reticulum stress. Antioxid Redox Signal. 2009;11(9):2333-9.

34. Tabas I. Macrophage death and defective inflammation resolution in atherosclerosis. Nature reviews Immunology. 2010;10(1):36-46.

35. Halvorsen B, Holm S, Yndestad A, Scholz H, Sagen EL, Nebb H, et al. Interleukin-10 increases reverse cholesterol transport in macrophages through its bidirectional interaction with liver $\mathrm{X}$ receptor alpha.

Biochemical and biophysical research communications. 2014;450(4):1525-30.

36. Shouval DS, Biswas A, Goettel JA, McCann K, Conaway E, Redhu NS, et al. Interleukin-10 receptor signaling in innate immune cells regulates mucosal immune tolerance and anti-inflammatory macrophage function. Immunity. 2014;40(5):706-19.

37. Metghalchi S, Ponnuswamy P, Simon T, Haddad Y, Laurans L, Clement M, et al. Indoleamine 2,3Dioxygenase Fine-Tunes Immune Homeostasis in Atherosclerosis and Colitis through Repression of Interleukin10 Production. Cell metabolism. 2015;22(3):460-71.

38. Zigmond E, Bernshtein B, Friedlander G, Walker CR, Yona S, Kim KW, et al. Macrophage-restricted interleukin-10 receptor deficiency, but not IL-10 deficiency, causes severe spontaneous colitis. Immunity. 2014;40(5):720-33.

39. Glocker EO, Kotlarz D, Klein C, Shah N, Grimbacher B. IL-10 and IL-10 receptor defects in humans. Annals of the New York Academy of Sciences. 2011;1246:102-7.

40. Mahler M, Leiter EH. Genetic and environmental context determines the course of colitis developing in IL-10-deficient mice. Inflammatory bowel diseases. 2002;8(5):347-55.

41. Mallat Z, Besnard S, Duriez M, Deleuze V, Emmanuel F, Bureau MF, et al. Protective role of interleukin10 in atherosclerosis. Circulation research. 1999;85(8):e17-24. 
42. Potteaux S, Deleuze V, Merval R, Bureau MF, Esposito B, Scherman D, et al. In vivo electrotransfer of interleukin-10 cDNA prevents endothelial upregulation of activated NF-kappaB and adhesion molecules following an atherogenic diet. European cytokine network. 2006;17(1):13-8. 43. Zemse SM, Chiao CW, Hilgers RH, Webb RC. Interleukin-10 inhibits the in vivo and in vitro adverse effects of TNF-alpha on the endothelium of murine aorta. American journal of physiology Heart and circulatory physiology. 2010;299(4):H1160-7.

44. Gareus R, Kotsaki E, Xanthoulea S, van der Made I, Gijbels MJ, Kardakaris R, et al. Endothelial cellspecific NF-kappaB inhibition protects mice from atherosclerosis. Cell metabolism. 2008;8(5):372-83. Crohn's disease with recombinant human interleukin 10 induces the proinflammatory cytokine interferon gamma. Gut. 2002;50(2):191-5. metabolism: relevance for efficacy of anti-inflammatory drugs in the treatment of atherosclerosis. Atherosclerosis. 2013;228(2):306-15. 


\section{Legends to figures and tables}

Table 1. Basal characteristics of wildtype and IL-10R1-deficient mice upon 10 weeks chow and highcholesterol diet. ${ }^{a}$ indicates $p<0.01,{ }^{b}$ indicates $p<0.0001$.

Table 2. IL-10R1 ${ }^{\text {del }}$ mice display a reproducible phenotype upon 6 weeks high-cholesterol feeding. NOTE. Certain measurements were not available $(n / a)$ at $t=0 .{ }^{a}$ indicates $p<0.01,{ }^{b}$ indicates $p<0.0001$.

Table 3. Hepatobiliary output parameters after 6 weeks HCD are comparable between IL-10R1 ${ }^{\text {wt }}$ and IL10R1 ${ }^{\text {del }}$ mice.

Figure 1. Myeloid IL-10R1-deficiency attenuates atherosclerotic plaque size and severity and alters cholesterol handling. (A) Representative photographs of toluidine blue-stained aortic roots from highcholesterol fed IL-10R1 ${ }^{\text {wt }}$ and IL-10R1 ${ }^{\text {del }}$ mice (x40). (B) Quantification of lesion area in aortic roots from IL$10 R 1^{\text {wt }}$ and IL-10R1 ${ }^{\text {del }}$ mice upon 10 weeks HCD, $n=18$ /group. (C) Pie diagrams of lesion distribution in IL-10R $1^{\text {wt }}$ and IL-10R $1^{\text {del }}$ mice into early, moderate or advanced lesions, $n=18 /$ group. Data were tested using the Chisquare test. (D) Quantification of plaque collagen content by Sirius Red staining. Data are presented as a percentage of total lesion area, $n=18$ /group. (E) Quantification of TUNEL $^{+}$cells in atherosclerotic lesions, n=18/group. (F) Representative photographs of ORO-stained aortic roots of wildtype and IL-10R1 deleted mice. (G) Quantification of neutral lipid content, $n=18$ /group. (H, I) OxLDL uptake by wildtype and IL-10R1 deficient BMMs upon 3 hours incubation with $12.5 \mathrm{mg} / \mathrm{ml}$ Dil-labelled oxLDL in OPTIMEM-medium in the presence or absence of $10 \mathrm{ng} / \mathrm{ml} \alpha \mathrm{LL}-10, \mathrm{n}=3 /$ group $(\mathrm{H})$ Representative histograms of positive counts in both genotypes. (J, K) Gene expression analysis of oxLDL-loaded IL-10R $1^{\text {wt }}$ and IL-10R $1^{\text {del }}$ BMMs for scavenger receptors (CD36, SRA) and efflux transporters ( $A B C A 1, A B C G 1), n=3$ /group. Data represents means $\pm S E M$, and data were tested using the students t-test.

\section{Figure 2. Myeloid IL-10R1 deficiency limits macrophage and neutrophil accumulation in plaques, but does not} affect systemic inflammation. (A) Circulating plasma levels of mouse inflammatory cytokines in both genotypes, $n=10 /$ group. (B) Aortic arch gene expression of CD68 and (C) of inflammatory cytokines, $n=16 /$ group. (D-E) Representative photographs of aortic root staining and quantification of macrophages after 10 weeks of $H C D$ and $(F-G)$ recently infiltrated myeloid cells and $(H-I)$ neutrophils after both 6 and 10 weeks of HCD, with $n=9$ /group for 6 weeks $n=18$ /group for 10 weeks HCD. Data represents means \pm SEM, and data were tested using the students t-test.

Figure 3. Myeloid IL-10R1 deficiency attenuates hyperlipidemia in LDLR ${ }^{-/-}$mice. (A) Liver total cholesterol and triglyceride levels in both groups of mice, $n=8-9 / g r o u p . ~(B, C)$ Lipoprotein profiles from pooled plasma samples of IL-10R $1^{\text {wt }}$ and IL-10R1 ${ }^{\text {del }}$ mice on chow and upon 10 weeks HCD. (D) Gene expression levels of hepatic genes involved in cholesterol metabolism, expressed as fold change of IL-10R $1^{\text {del }}$ mice compared to wildtype animals 
with associated $p$-value (dots), $n=8 /$ group. (E, F) Plasma lanosterol- and lathosterol-to-cholesterol ratios and campesterol- and cholestanol-to-cholesterol ratios as respective markers of cholesterol biosynthesis and intestinal absorption in IL-10R $1^{\mathrm{wt}}$ and IL-10R $1^{\mathrm{del}}$ mice, $\mathrm{n}=16-15 /$ group. Data represent mean $\pm \mathrm{SEM}$, and data were tested using the students t-test.

661

Figure 4. Myeloid IL-10R1-deficiency alters systemic cholesterol fluxes in hyperlipidaemic LDLR $^{-/-}$mice. (A) Percentage of cholesterol biosynthesis upon 6 weeks of HCD. (B) Relative mRNA expression for HMG-coA reductase in liver and proximal small intestine samples of IL-10R1 ${ }^{\text {del }}$ mice vs. wildtype mice upon 6 weeks of HCD. (C) Percentage of cholesterol absorption and (D) faecal loss upon 6 weeks of HCD. (E) Linear regression analysis of faecal neutral sterol excretion vs. plasma cholesterol levels. (F) Non-biliary cholesterol efflux upon 6 weeks of HCD. (G) Hepatic gene expression of bile acid synthesizing enzymes. Data represent mean \pm SEM with $\mathrm{n}=7-9 /$ group, and data were tested using the students $\mathrm{t}$-test.

669

Figure 5. Myeloid IL-10R1-deficiency decreases esterification of cholesterol in plasma lipoproteins. (A, B) Cholesteryl ester/free cholesterol ratio in plasma and liver lipoproteins after 6 weeks of HCD. (C) Relative ACAT2 gene expression in primary murine macrophages. (D) Relative ACAT2 gene expression in liver and proximal small intestine following 6 weeks of HCD. (E) Linear regression analysis of faecal neutral sterol excretion vs. mRNA expression of ACAT2 in proximal small intestine. Data represent mean \pm SEM of $n=7$ -

676

677

678

679

680

681

682

683

684

685

686

687

688

689

690 
Table I

\begin{tabular}{|c|c|c|c|c|c|c|}
\hline \multirow[b]{2}{*}{ Basal characteristics } & \multicolumn{2}{|c|}{ chow diet } & \multicolumn{2}{|c|}{ 4w HCD } & \multicolumn{2}{|c|}{$10 \mathrm{w} \mathrm{HCD}$} \\
\hline & IL-10R1 $^{\text {wt }}$ & IL-10R1 $^{\text {del }}$ & IL-10R1 $^{\text {wt }}$ & IL-10R1 ${ }^{\text {del }}$ & IL-10R1 $^{\text {wt }}$ & IL-10R1 ${ }^{\text {del }}$ \\
\hline Bodyweight (g) & $17.9 \pm 0.2$ & $18.3 \pm 0.3$ & $20.4 \pm 0.1$ & $21.0 \pm 0.1$ & $21.6 \pm 0.3$ & $21.5 \pm 0.3$ \\
\hline Cholesterol (mM) & $8.60 \pm 0.30$ & $7.62 \pm 0.27^{\mathrm{a}}$ & $30.68 \pm 1.58$ & $20.12 \pm 1.18^{b}$ & $37.07 \pm 2.78$ & $25.72 \pm 1.39^{b}$ \\
\hline Triglycerides (mM) & $0.49 \pm 0.03$ & $0.57 \pm 0.04$ & $1.02 \pm 0.08$ & $0.89 \pm 0.06$ & $0.85 \pm 0.07$ & $0.75 \pm 0.04$ \\
\hline
\end{tabular}

693

694

Table II

\begin{tabular}{|c|c|c|c|c|}
\hline \multirow[b]{3}{*}{ Basal characteristics } & \multicolumn{2}{|c|}{ chow diet } & \multicolumn{2}{|c|}{ high-cholesterol diet } \\
\hline & IL-10R1 $^{\text {wt }}$ & IL-10R1 $^{\text {deI }}$ & IL-10R1 $^{\text {wt }}$ & IL-10R1 $^{\text {deI }}$ \\
\hline & & & & \\
\hline Plasma cholesterol (mM) & $7.2 \pm 0.3$ & $6.6 \pm 0.1$ & $36.9 \pm 2.6$ & $23.5 \pm 3.2^{a}$ \\
\hline Plasma triglycerides (mM) & $1.0 \pm 0.1$ & $0.9 \pm 0.2$ & $2.6 \pm 0.2$ & $1.5 \pm 0.2^{\mathrm{a}}$ \\
\hline Bodyweight (g) & $17.9 \pm 0.2$ & $18.3 \pm 0.3$ & $21.6 \pm 0.3$ & $21.5 \pm 0.3$ \\
\hline Liver weight (g) & $\mathrm{n} / \mathrm{a}$ & $\mathrm{n} / \mathrm{a}$ & $1.1 \pm 0.04$ & $1.0 \pm 0.04$ \\
\hline 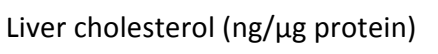 & $\mathrm{n} / \mathrm{a}$ & $\mathrm{n} / \mathrm{a}$ & $40.4 \pm 1.7$ & $25.3 \pm 1.3^{b}$ \\
\hline Liver triglycerides ( $\mathrm{ng} / \mu \mathrm{g}$ protein) & $\mathrm{n} / \mathrm{a}$ & $\mathrm{n} / \mathrm{a}$ & $143.6 \pm 9.4$ & $143.1 \pm 9.0$ \\
\hline Food intake $(\mathrm{g} / \mathrm{d})$ & $\mathrm{n} / \mathrm{a}$ & $\mathrm{n} / \mathrm{a}$ & $2.4 \pm 0.1$ & $2.6 \pm 0.2$ \\
\hline Faecal output (g/d) & $\mathrm{n} / \mathrm{a}$ & $\mathrm{n} / \mathrm{a}$ & $0.3 \pm 0.01$ & $0.4 \pm 0.04^{b}$ \\
\hline
\end{tabular}

696

697

698

Table III

\begin{tabular}{lcc}
\hline & IL-10R1 $^{\text {wt }}$ & IL-10R1 $^{\text {del }}$ \\
\hline Bile flow $(\mu \mathrm{l} / \mathrm{min})$ & $0.7 \pm 0.1$ & $0.8 \pm 0.1$ \\
Cholesterol $(\mathrm{nmol} / \mathrm{min})$ & $0.4 \pm 0.06$ & $0.3 \pm 0.03$ \\
Phospholipids $(\mathrm{nmol} / \mathrm{min})$ & $5.7 \pm 0.6$ & $5.3 \pm 0.4$ \\
Bile acids $(\mathrm{nmol} / \mathrm{min})$ & $38.9 \pm 8.6$ & $37.7 \pm 7.9$ \\
\hline
\end{tabular}


Figure 1

A

IL-10R1 ${ }^{\mathrm{mt}}$

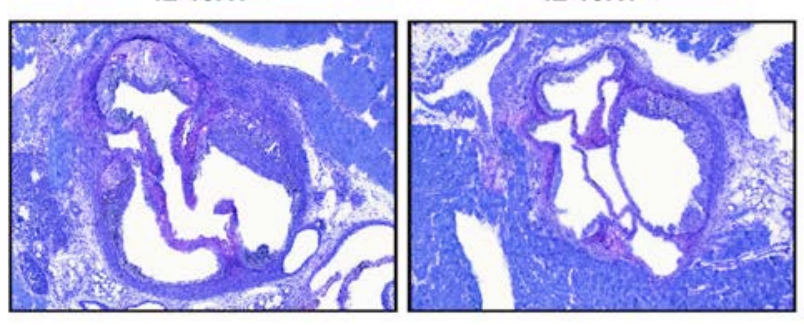

C

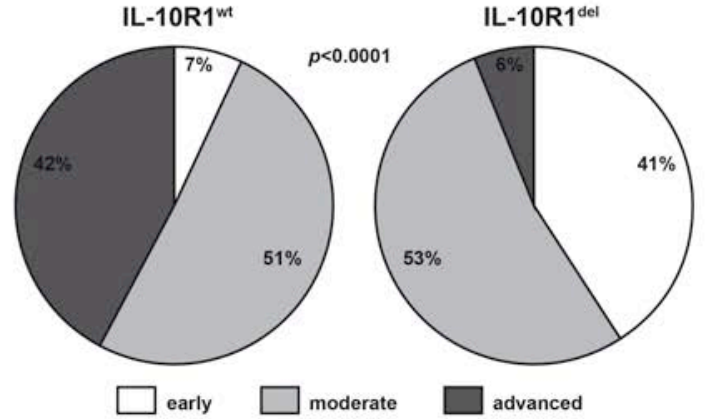

F

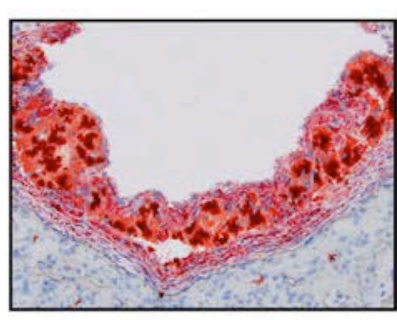

IL-10R1 del

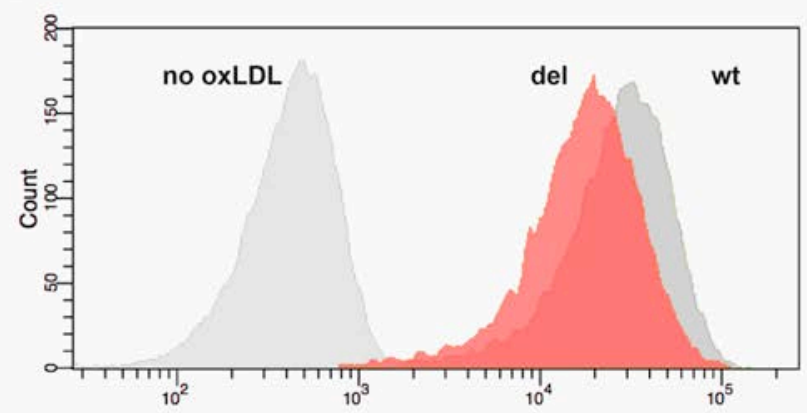

B

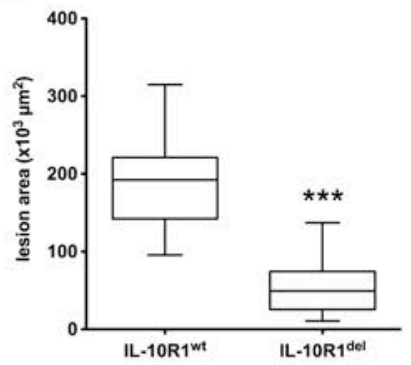

D

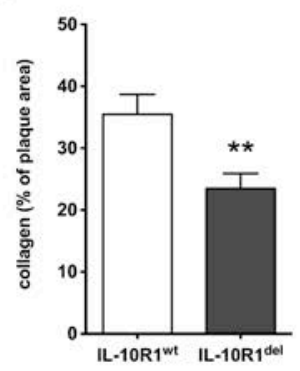

E

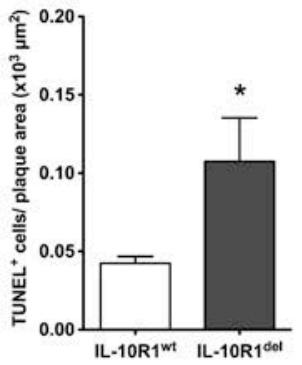

G

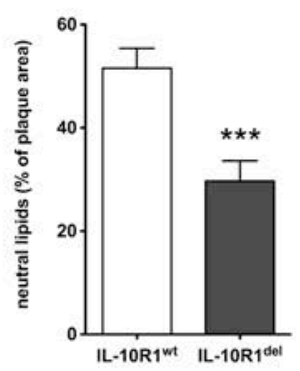

$\mathrm{H}$

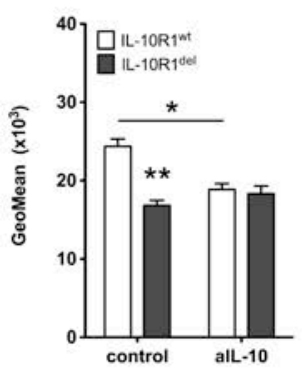

K
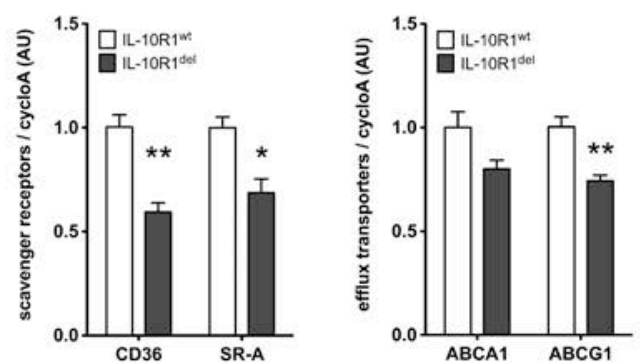
A

B C
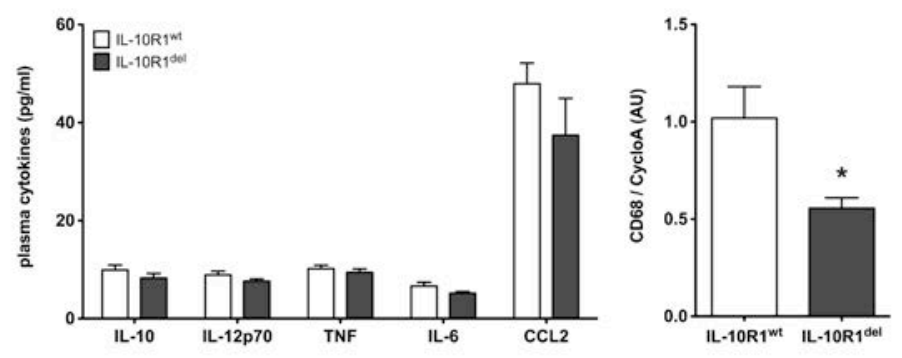

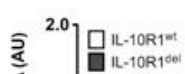

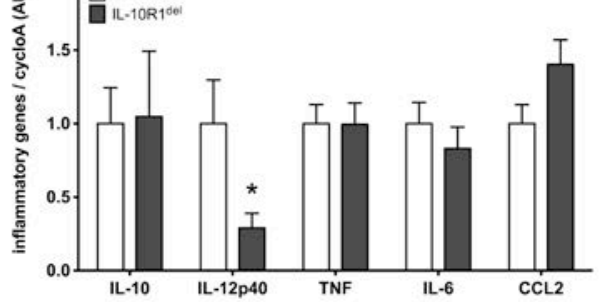

D

IL-10R 1 $^{\mathrm{m}}$

IL-10R1 del
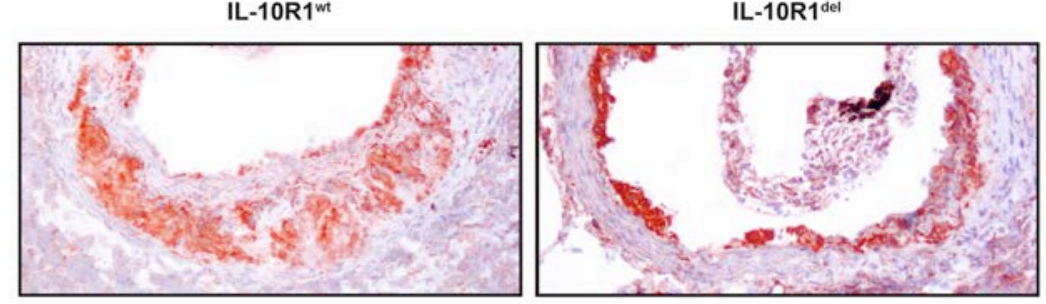

E

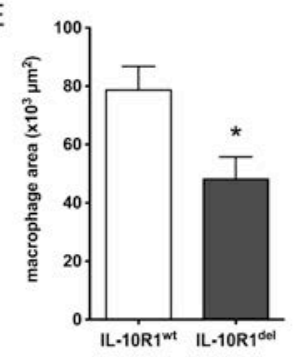

F

IL-10R 1 $^{\text {t }}$

$\mathrm{IL}-10 \mathbf{R}^{\text {del }}$
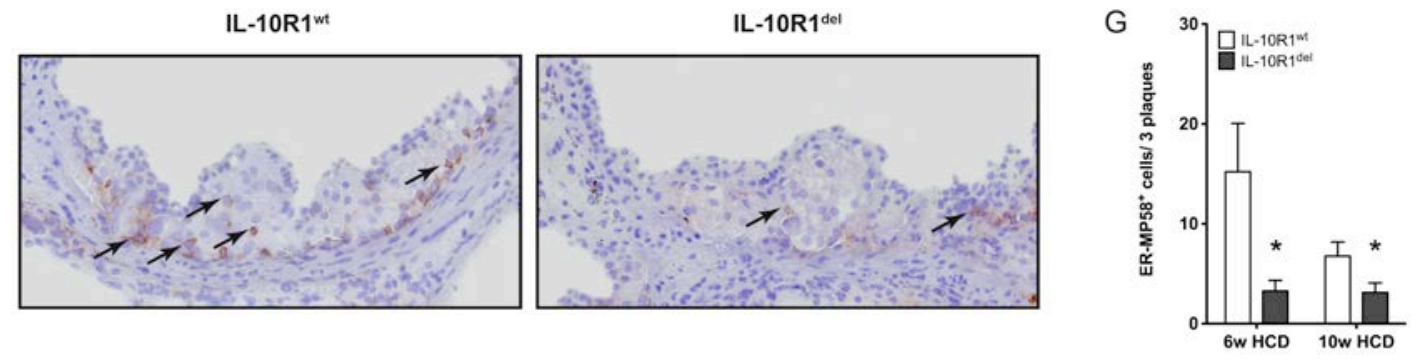

$\mathrm{H}$

IL-10R $1^{\text {wt }}$

IL-10R1 $1^{\text {del }}$
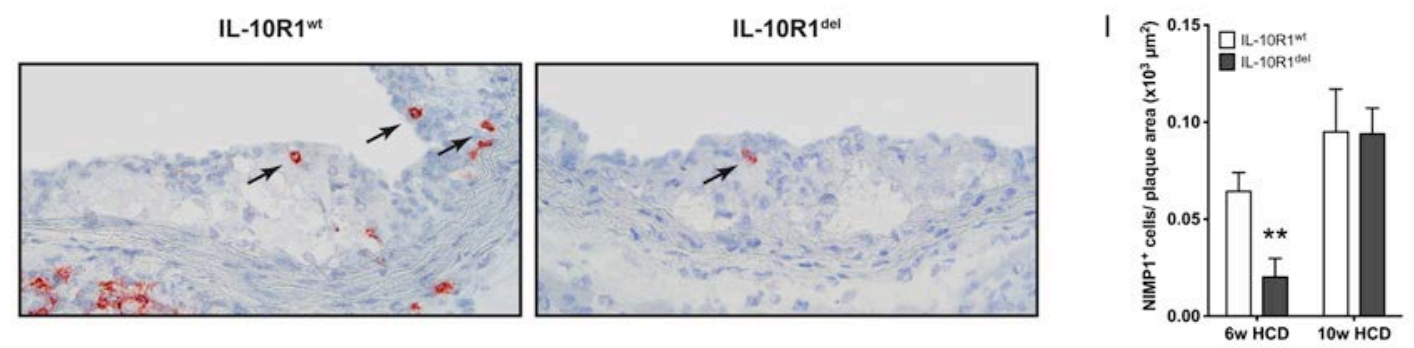
A

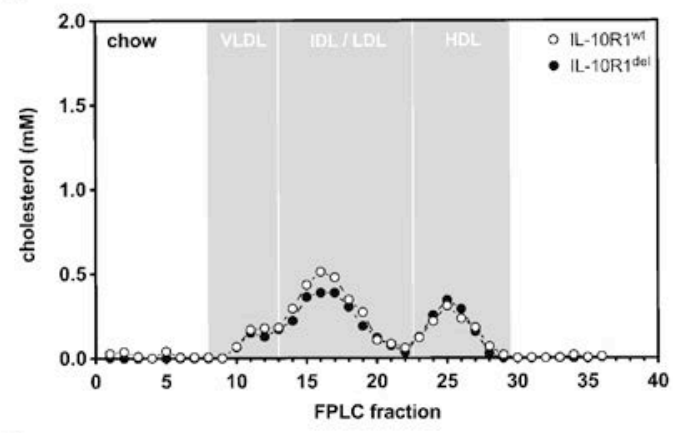

C

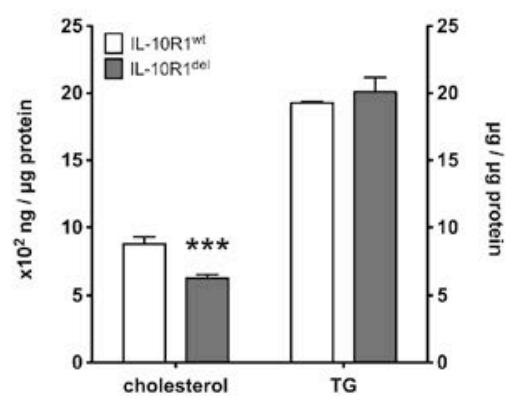

E
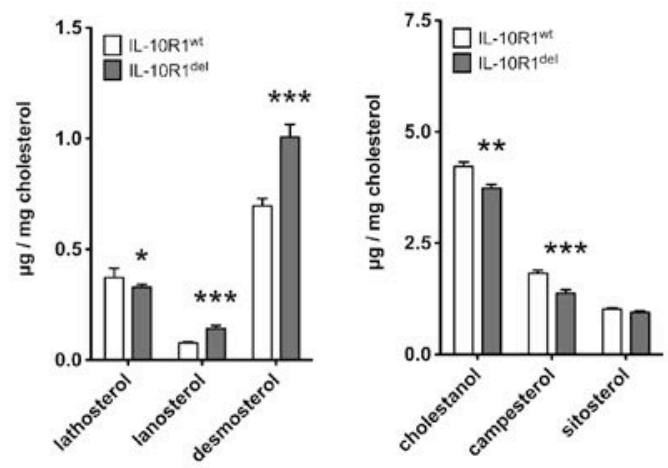

B

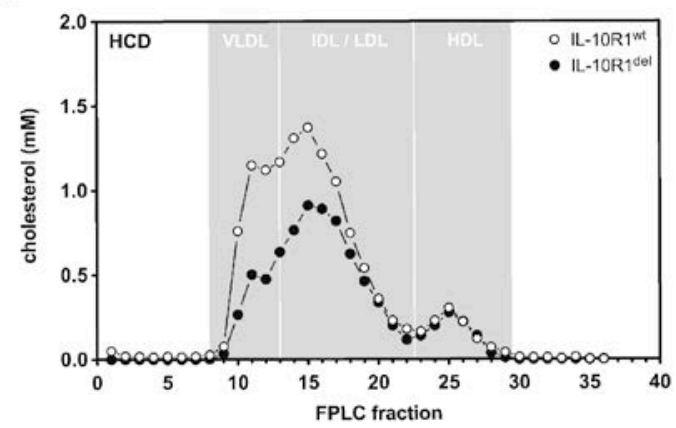

D

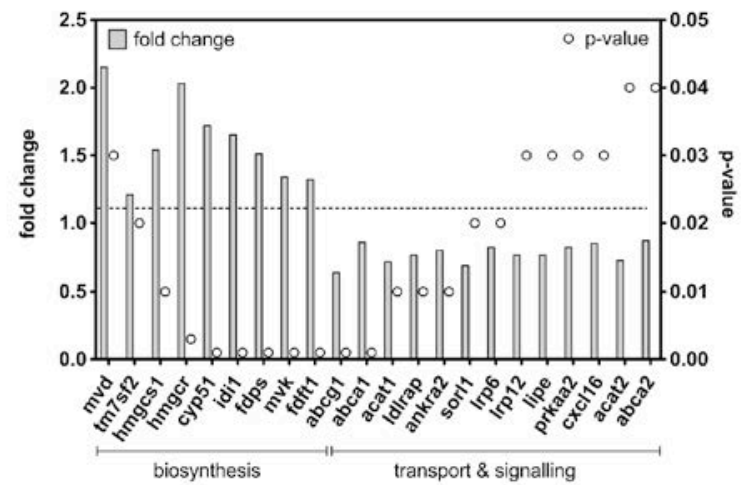


A

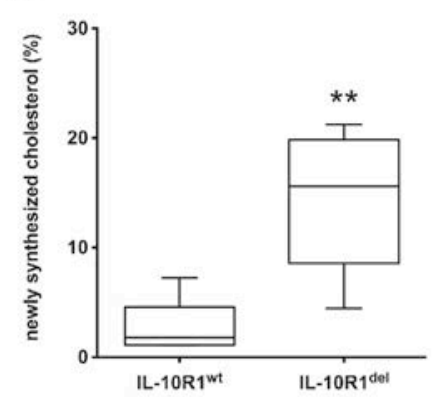

D

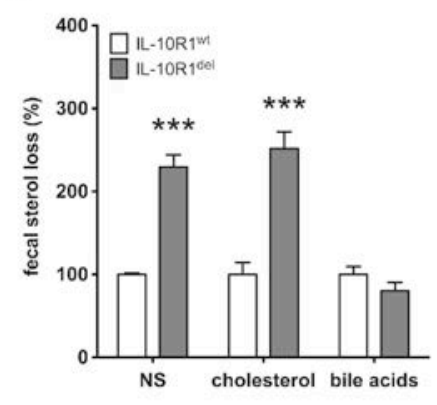

F

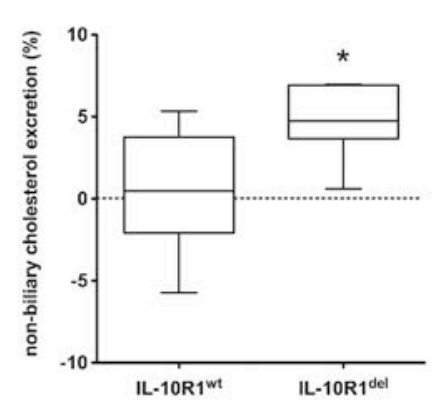

B

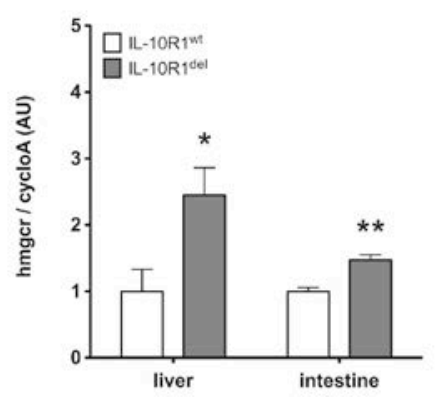

E

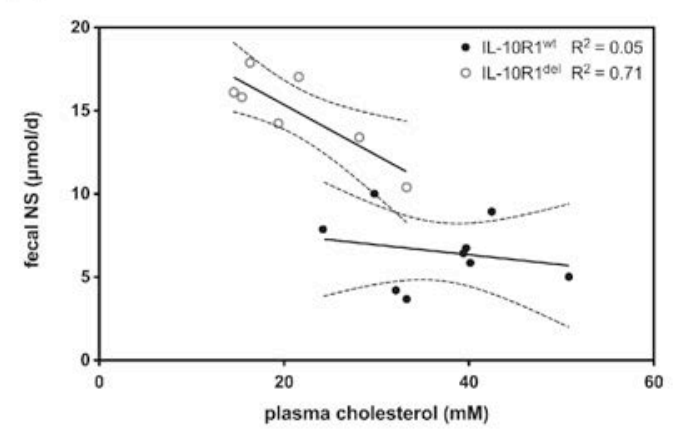

G

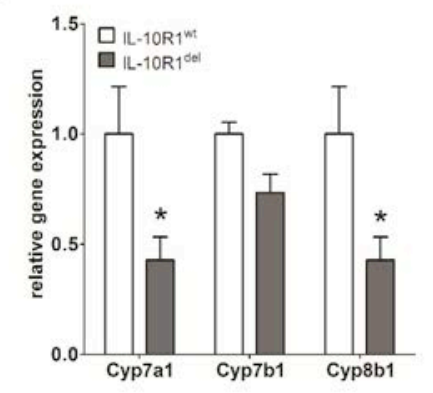


A

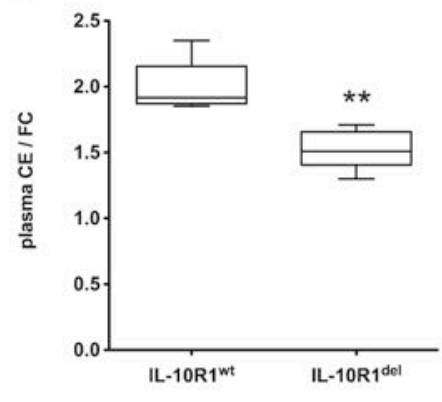

D

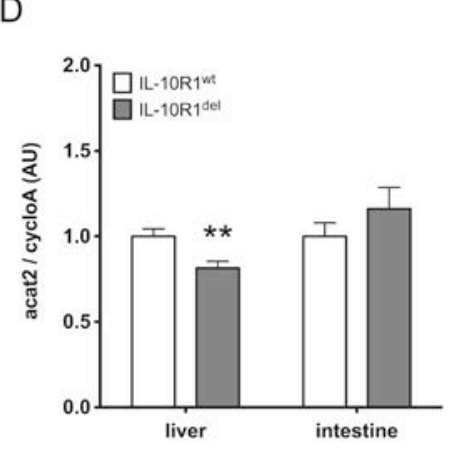

B

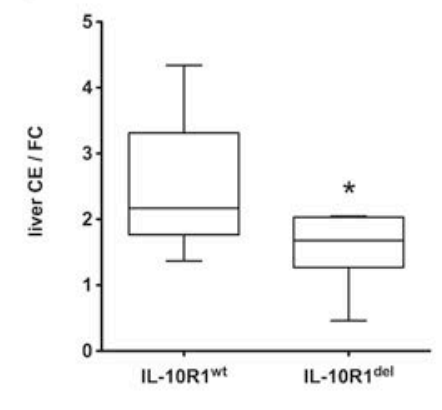

E

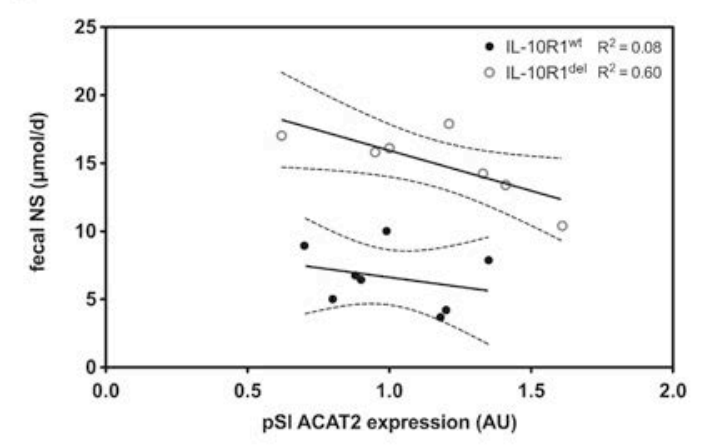

C

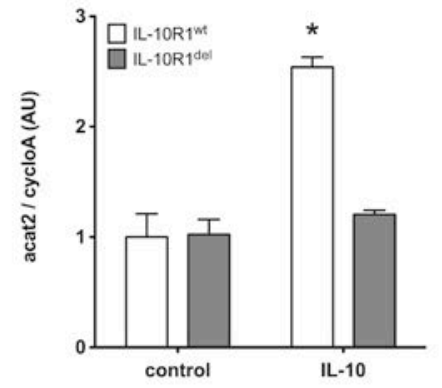

ara 